\title{
Effect of Apricot Almond Oil as Green Inhibitor for Steel Corrosion in Hydrochloric Media
}

\author{
A. Batah ${ }^{a}$, A. Anejjar ${ }^{a}$, L. Bammou ${ }^{a}$, M. Belkhaouda ${ }^{a, b, *}$ and R. Salghi ${ }^{a}$ \\ ${ }^{a}$ aLaboratory of Environmental Engineering and Biotechnology, ENSA, Ibn Zohr University, \\ P.O. Box 1136, 80000 Agadir, Morocco \\ ${ }^{b}$ Regional Centre for Education and Training, Souss Massa, Inzegane, Morocco
}

Received January 15, 2018; accepted April 15, 2018

\begin{abstract}
Natural oil extracted from apricot seeds was evaluated as carbon steel corrosion inhibitor in $1 \mathrm{M}$ hydrochloric acid, using potentiodynamic polarization, electrochemical impedance spectroscopy (EIS) and weight loss measurements. The measurements show that apricot seed oil is a good inhibitor for carbon steel corrosion in a hydrochloric environment, and this inhibitive action was mainly due to its adsorption onto the carbon steel surface, and active sites blocking. The above results showed that apricot seed oil acted as a mixed-type corrosion inhibitor, and that its adsorption onto the carbon steel surface obeyed the Langmuir adsorption isotherm. The inhibition effectiveness increased with the inhibitor concentration, and reached $83.49 \%$ at $0.5 \mathrm{~g} / \mathrm{L}$, in a 1 $\mathrm{M} \mathrm{HCl} \mathrm{medium.} \mathrm{Some} \mathrm{thermodynamic} \mathrm{parameters} \mathrm{of} \mathrm{the} \mathrm{studied} \mathrm{inhibitor} \mathrm{were}$ calculated and discussed.
\end{abstract}

Keywords: corrosion, inhibition, apricot almond oil, electrochemical studies, carbon steel.

\section{Introduction}

Corrosion is a fundamental process playing an important role in economics and safety, particularly for metals and alloys. Steel alloys are well-known materials used in various industrial applications, highly susceptible to dissolution problems in aqueous solutions, and especially in acidic media. Steel has found wide application in a broad spectrum of industries and machinery, despite its tendency to corrosion. The use of inhibitors is a practical technique to secure metals and alloys from aggressive environments. Many organic compounds containing N, S and $P$ revealed an excellent efficiency against the corrosion of metals and their alloys. However, these products are generally obtained by chemical synthesis and, therefore, have a negative impact on the environment. This has led many researchers around the world to use new natural molecules, non-polluting to the

\footnotetext{
*Corresponding author. E-mail address: m.belkhaouda@uiz.ac.ma
} 
environment. However, most of these compounds are not only expensive [1-4], but also toxic to living beings. Recently, research in corrosion has been focused on green corrosion inhibitors, namely, eco-friendly inhibitors that show good inhibition efficiency, with low risk of environmental pollution, and decreased costs [5-9].

The aim of this work was to study the effect of apricot almond oil on carbon steel corrosion in $1.0 \mathrm{M} \mathrm{HCl}$, using potentiodynamic polarization curve tests, electrochemical impedance spectroscopy (EIS) and gravimetric measurements.

\section{Materials and methods \\ Materials}

The carbon steel used in this study has C35E Euronorm, and SAE 1035 US specification, with a chemical composition (in $\mathrm{wt} \%$ ) of $0.370 \% \mathrm{C}, 0.230 \% \mathrm{Si}$, $0.680 \% \mathrm{Mn}, 0.016 \% \mathrm{~S}, 0.077 \% \mathrm{Cr}, 0.011 \% \mathrm{Ti}, 0.059 \% \mathrm{Ni}, 0.009 \% \mathrm{Co}$, $0.160 \% \mathrm{Cu}$, and the remainder iron $(\mathrm{Fe})$. The acid solutions $(1.0 \mathrm{M} \mathrm{HCl})$ were prepared by dilution of an analytical reagent grade, $37 \% \mathrm{HCl}$, with doubledistilled water. The extraction of the essential oil was conducted by hydrodistillation, using a Clevenger type apparatus. The obtained essential oil was dried under anhydrous sodium sulfate, and stored at $4{ }^{\circ} \mathrm{C}$, in the dark, before analysis. The concentration range of the employed apricot almond oil (AAO) was $0.05 \mathrm{~g} / \mathrm{L}$ to $0.5 \mathrm{~g} / \mathrm{L}$.

\section{Measurements}

\section{Weight loss measurements}

Gravimetric measurements were performed after $6 \mathrm{~h}$, at the temperature of $298 \mathrm{~K}$, using an analytical balance (precision $\pm 0.1 \mathrm{mg}$ ). The used C38 steel specimens were rectangular in shape (length $=1.6 \mathrm{~cm}$, width $=1.6 \mathrm{~cm}$ and thickness $=0.07 \mathrm{~cm}$ ). Gravimetric experiments were performed in a double glass cell equipped with a thermostated cooling condenser containing $80 \mathrm{~mL}$ of the non-de-aerated test solution. After immersion, the C38 steel specimens were withdrawn, carefully rinsed with bidistilled water, ultrasonically cleaned in acetone, dried at room temperature, and then weighed. Triplicate experiments were performed in each case, and the mean value of the weight loss was calculated.

\section{Electrochemical measurements}

The electrochemical study was carried out using a PGZ100 potentiostat piloted by Voltamaster 4 software. A conventional three-electrode cylindrical pyrex glass cell was used. The temperature was thermostatically controlled. The working electrode was C38 steel, with a surface area of $0.84 \mathrm{~cm}^{2}$. A saturated calomel electrode (SCE) was used as reference. The counter electrode was a platinum plate with a surface area of $1 \mathrm{~cm}^{2}$.

For polarization curves, the working electrode was immersed in the test solution for $30 \mathrm{~min}$, or until a steady-state open circuit potential $\left(\mathrm{E}_{\mathrm{ocp}}\right)$ was obtained. The 
polarization curve was recorded by polarization, from -800 to $-200 \mathrm{mV} / \mathrm{SCE}$, with a scan rate of $1 \mathrm{mVs}^{-1}$. AC impedance measurements were performed in the frequency range from $100 \mathrm{kHz}$ to $10 \mathrm{mHz}$, with 10 points per decade, at the rest potential, after immersion in acid for $30 \mathrm{~min}$, by applying $10 \mathrm{mV}$ peak-to-peak AC voltage. Nyquist plots were obtained from these experiments. To produce the Nyquist plot, the data points were fitted to the best semicircle, using a non-linear least square fit, to give the intersections with the $\mathrm{X}$-axis.

\section{Results and discussion}

\section{Analyzing the oil chemical composition}

The chromatography gas analysis of apricot almond oil allowed the identification of its composition. The essential oil mainly contains bioactive substances: 98.13\% of its compounds are shown in Fig. 1 and Table 1. According to the analysis results, oleic acid was the most abundant oil component $(62.17 \%)$. Other main oil components were linoleic $(28.15 \%)$, palmitic $(5.45 \%)$ and stearic $(1.28 \%)$ acids.

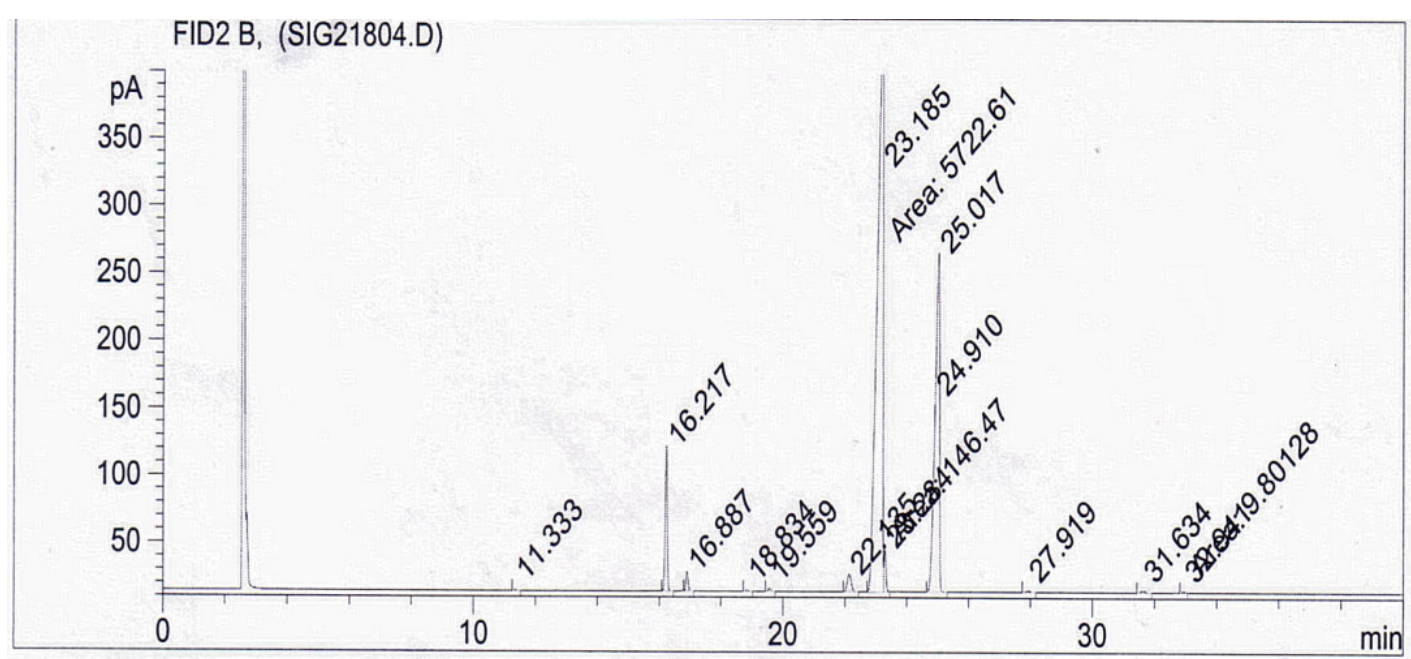

Figure 1. Chromatogram of the apricot almond oil extract.

Table 1. Chemical composition (\%) of the apricot almond oil extract.

\begin{tabular}{ccc}
\hline Fatty acid & Common acid name & $\mathbf{( \% )}$ \\
\hline C16:0 & Palmitic acid & $5.45 \pm 0.05$ \\
C16:1 & Palmitoleic acid & $0.79 \pm 0.02$ \\
C17:0 & Heptadecanoic acid & $0.047 \pm 0.01$ \\
C18:0 & Stearic acid & $1.28 \pm 0.02$ \\
C18:1 & Oleic acid & $62.17 \pm 0.12$ \\
C18:2 & Linoleic acid & $28.15 \pm 0.10$ \\
C18:3 & $\alpha$-Linolenic acid & $0.09 \pm 0.01$ \\
C20:0 & Arachidic acid & $0.14 \pm 0.02$ \\
C20:1 & Gadoleic acid & $0.10 \pm 0.02$ \\
\hline
\end{tabular}

Electrochemical impedance spectroscopy measurements (EIS)

Steel corrosion behavior in an acidic solution, with and without apricot almond oil, was also investigated by electrochemical impedance spectroscopy (EIS), at 
$298 \mathrm{~K}$, after $30 \mathrm{~min}$ of immersion. Carbon steel Nyquist plots obtained at the interface, in the presence and absence of AAO extract, at different concentrations, are given in Fig. 2. The charge transfer resistance $\left(\mathrm{R}_{\mathrm{ct}}\right)$ values were calculated by subtracting the high frequency intersection from the low frequency intersection [10]. $R_{c t}$ values were obtained from these plots, by determining the difference in the impedance values, at low and high frequencies [11].

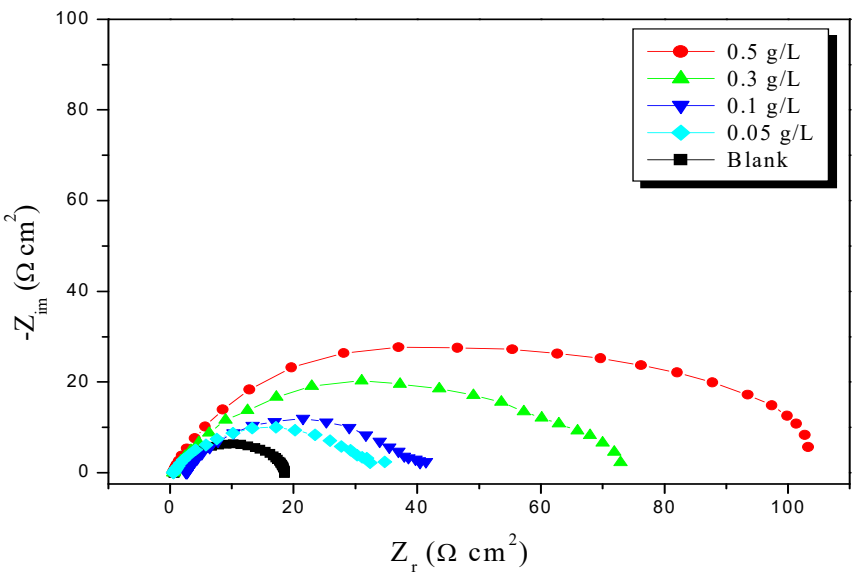

Figure 2. Nyquist plots for carbon steel corrosion in $1.0 \mathrm{M} \mathrm{HCl}$ with different concentrations of apricot almond oil extract, at $298 \mathrm{~K}$.

Double layer capacitance $\left(\mathrm{C}_{\mathrm{dl}}\right)$ values were calculated using the following equation:

$$
c_{d l}=\left(2 \pi \cdot f_{\max } \cdot R_{c t)}\right)^{-1}
$$

where $C_{\mathrm{dl}}$ is the double layer capacitance $\left(\mu \mathrm{F} . \mathrm{cm}^{-2}\right), \mathrm{f}_{\max }$ is the maximum frequency $(\mathrm{Hz})$ and $\mathrm{R}_{\mathrm{ct}}$ is the charge transfer resistance $\left(\Omega . \mathrm{cm}^{2}\right)$.

Impedance diagrams were obtained for the frequency range from $100 \mathrm{kHz}$ to 10 $\mathrm{mHz}$, at the open circuit potential, for carbon steel in $1.0 \mathrm{M} \mathrm{HCl}$, with and without AAO extract. Nyquist plots for carbon steel in acidic media, at various concentrations of AAO extract, are presented in Fig. 2. Table 2 gives charge transfer resistance $\left(\mathrm{R}_{\mathrm{ct}}\right)$, double layer capacitance $\left(\mathrm{C}_{\mathrm{dl}}\right)$, and $\mathrm{f}_{\max }$ values derived from Nyquist plots, and the inhibition efficiency obtained from the charge transfer resistance was calculated by the following equation:

$$
\mathrm{E}_{\mathrm{RT}}(\%)=\left(1-\frac{\mathrm{R}_{\mathrm{ct}}^{\mathrm{r}}}{\mathrm{R}_{\mathrm{ct}}}\right) \times 100
$$

where $R_{c t}$ and $R_{\text {ct }}$ are the charge transfer resistance values, without and with inhibitor, respectively.

Generally, Fig. 2 shows that the impedance spectra reveal a similar semicircle shape of the curves. The shape is maintained throughout the whole concentration, indicating that almost no change in the corrosion mechanism occurred due to the inhibitor addition [12], and that the semicircles diameters increased with the 
inhibitor concentration. The obtained impedance diagrams are semi-circular in appearance, which can be attributed to the charge transfer that takes place at the electrode/solution interface. The transfer process controlled carbon steel corrosion reaction, and the inhibitor presence did not change the steel dissolution mechanism [13-14]. It is also clear that these impedance diagrams consist of one large capacitive loop; they are not perfect semicircles, and deviations of a perfect circular shape are often referred to the frequency dispersion of interfacial impedance. This anomalous phenomenon is interpreted by the inhomogeneity of the electrode surface arising from surface roughness, or from interfacial phenomena [15-16].

Table 2. Electrochemical impedance parameters for steel corrosion in an acidic medium, at various contents of apricot almond oil extract.

\begin{tabular}{|c|c|c|c|c|}
\hline Inhibitor & $\begin{array}{c}C \\
(g / L)\end{array}$ & $\begin{array}{c}\mathbf{R}_{\mathrm{ct}} \\
\left(\mathbf{\Omega . c m}^{2}\right)\end{array}$ & $\begin{array}{c}\mathbf{C}_{\mathrm{dl}} \\
\left(\mu \mathrm{F} / \mathbf{c m}^{2}\right)\end{array}$ & $\begin{array}{l}E_{\text {RT }} \\
(\%)\end{array}$ \\
\hline Blank & $1.0 \mathrm{~mol} / \mathrm{L}$ & 18 & 221 & - \\
\hline \multirow{4}{*}{ AAO } & $0.5 \mathrm{~g} / \mathrm{L}$ & 109 & 97 & 83.49 \\
\hline & $0.3 \mathrm{~g} / \mathrm{L}$ & 74 & 143 & 75.67 \\
\hline & $0.1 \mathrm{~g} / \mathrm{L}$ & 40 & 159 & 55 \\
\hline & $0.05 \mathrm{~g} / \mathrm{L}$ & 35 & 182 & 48.57 \\
\hline
\end{tabular}

From the inspection of Table 2 data, we notice an increase in the polarization resistance $\left(\mathrm{R}_{\mathrm{ct}}\right)$ and a decrease in the double layer capacitance $\left(\mathrm{C}_{\mathrm{dl}}\right)$, with higher inhibitor concentrations, which indicates that AAO extract inhibits mild steel corrosion rate by an adsorption mechanism [17]. The efficiency inhibition reached $83.49 \%$ at $0.5 \mathrm{~g} / \mathrm{L}$. Double layer capacitance values were also brought down to the maximum extent in the inhibitor presence, the decrease being more effective with a rise in concentration, and the decrease in $\mathrm{C}_{\mathrm{dl}}$ values followed a similar order to that obtained for $\mathrm{I}_{\text {corr }}$ studies. The decrease in $\mathrm{C}_{\mathrm{dl}}$ was due to this compound adsorption onto the metal surface, leading to the formation of a surface film in the acidic solution [18].

The results obtained from the polarization technique in an acidic solution were in good agreement with those obtained from the electrochemical impedance spectroscopy (EIS), with a small variation.

Excellent fit with this model was obtained with our experimental data (Fig. 3). It is observed that the fitted data matched the experimental, with an average error of about $0.01 \%$. $R_{\text {ct }}$ values were simultaneously determined by analysis of the complex-plane impedance plots and of the equivalent circuit model, and the results are very similar, with insignificant changes. The impedance spectra with one capacitive loop were analyzed by using the circuit in Fig. 4, and the $C_{d l}$ values were calculated from the frequency at which the impedance imaginary component (-Zi) was maximum, using equation (1).

The excellent fitting for EIS diagrams exposed in Fig. 3 can be achieved by using the equivalent circuit (Fig. 4). 

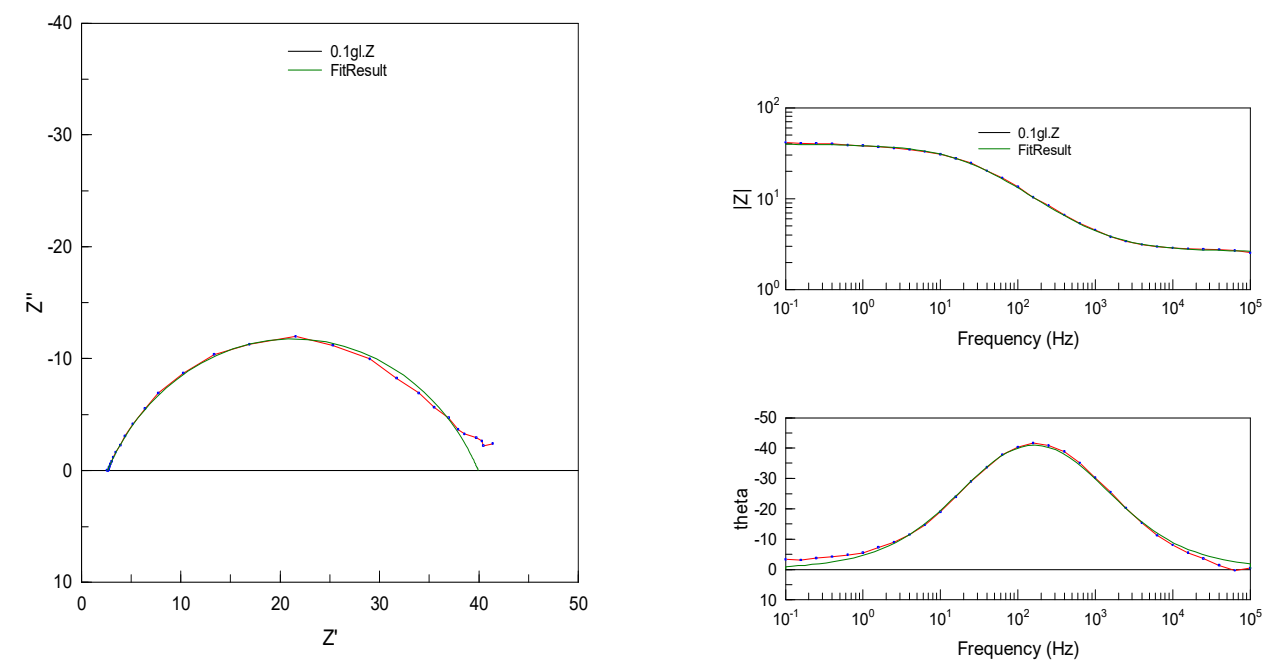

Figure 3. Experiment and fitting result for EIS diagrams.

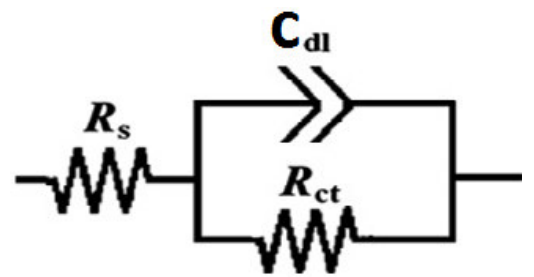

Figure 4. Equivalent circuit of the impedance spectra obtained for the inhibitors.

\section{Polarization results}

The anodic and cathodic polarization curves of carbon steel in a $1.0 \mathrm{M} \mathrm{HCl}$ solution, at $298 \mathrm{~K}$, in the absence and presence of various AAO concentrations, after 30 min of immersion time, are exposed in Fig. 5.

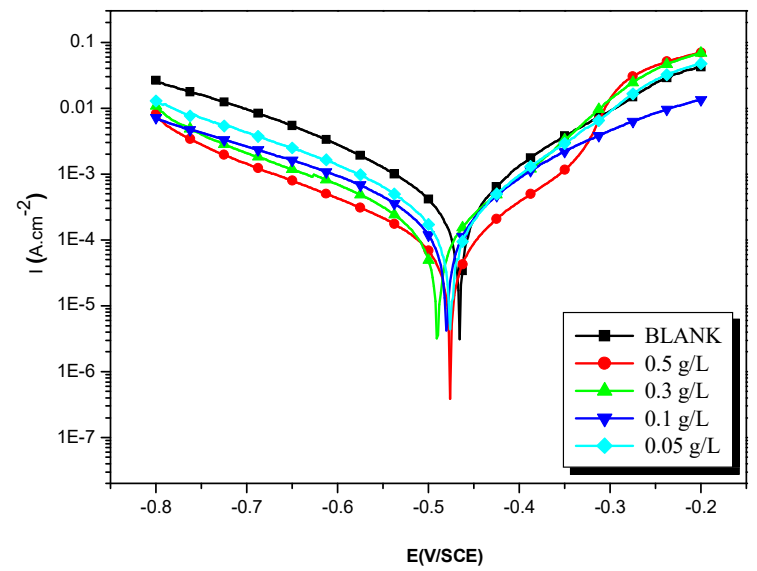

Figure 5. Polarization curves of carbon steel in $1.0 \mathrm{M} \mathrm{HCl}$, at various AAO concentrations, at $298 \mathrm{~K}$. 
From these curves, corrosion current density ( $\mathrm{I}_{\text {corr }}$ ) was graphically deduced by extrapolating the cathodic and anodic Tafel slope to the corrosion potential $\left(\mathrm{E}_{\mathrm{corr}}\right)$. The corrosion kinetic parameters and the percentage protection efficiency determined by the corrosion current density are listed in Table 3.

Table 3. Polarization data of carbon steel in $1.0 \mathrm{M} \mathrm{HCl}$, without and with various concentrations of apricot almond oil, at $298 \mathrm{~K}$.

\begin{tabular}{|c|c|c|c|c|c|c|}
\hline Inhibitor & Conc. & $\begin{array}{c}\text {-Ecorr } \\
(\mathrm{mV} / \mathrm{SCE})\end{array}$ & $\begin{array}{c}-\beta c \\
\left(m \mathbf{m ~ d e c}^{-1}\right)\end{array}$ & $\begin{array}{c}\boldsymbol{\beta a} \\
\left(\mathbf{m V} \operatorname{dec}^{-1}\right)\end{array}$ & $\begin{array}{c}\text { Icorr } \\
\left(\mu \mathrm{A} \mathrm{cm}^{-2}\right)\end{array}$ & $E_{I}(\%)$ \\
\hline Blank & $1.0 \mathrm{~mol} / \mathrm{L}$ & 463 & 168 & 123 & 636 & - \\
\hline \multirow{4}{*}{ AAO } & $0.5 \mathrm{~g} / \mathrm{L}$ & 476 & 194 & 108 & 103 & 84 \\
\hline & $0.3 \mathrm{~g} / \mathrm{L}$ & 489 & 196 & 96 & 157 & 75 \\
\hline & $0.1 \mathrm{~g} / \mathrm{L}$ & 479 & 215 & 106 & 290 & 54 \\
\hline & $0.05 \mathrm{~g} / \mathrm{L}$ & 470 & 202 & 104 & 336 & 47 \\
\hline
\end{tabular}

Comparing the curves for the inhibited with that of the uninhibited medium, it is observed that $\mathrm{E}_{\text {corr }}$ values for carbon steel in $1 \mathrm{M} \mathrm{HCl}$ slightly shifted towards a more positive direction, indicating that this compound can be classified as a mixed-style inhibitor, with anodic predominance. The cathodic diagrams (Fig. 5) show that AAO addition to the corrosive solution did not modify hydrogen reduction. The electrochemical data show that AAO molecules addition to the corrosion solution reduced the aggressiveness of this medium, per application, on both anodic metal dissolution and cathodic hydrogen evolution reactions. This behavior can be explained by the tested compound adsorption onto the electrode surface, which caused a barrier action for mass and charge transfer in both reactions [19]. The increase in the inhibition efficiency with AAO concentration justified the higher surface coverage obtained in the acidic solution with the optimum inhibitor concentration.

\section{Weight loss tests}

Steel corrosion rate $\left(\mathrm{W}_{\text {corr }}\right)$ in a $1.0 \mathrm{M} \mathrm{HCl}$ solution with various contents of the tested AAO was determined after $6 \mathrm{~h}$ of immersion period, at $298 \mathrm{~K}$. Corrosion rate and inhibition efficiency values are given in Table 4.

Table 4. Carbon steel weight loss data in $1.0 \mathrm{M} \mathrm{HCl}$ for various apricot almond oil concentrations.

\begin{tabular}{|c|c|c|c|c|}
\hline Inhibitor & Conc. & $\begin{array}{c}\mathbf{W}_{\text {corr }} \\
\mathbf{( m g . ~}^{-1} \mathbf{. c m}^{-\mathbf{2}} \mathbf{)}\end{array}$ & $\begin{array}{c}\mathbf{E}_{\mathbf{w}} \\
\mathbf{( \% )}\end{array}$ & $\boldsymbol{\theta}$ \\
\hline \multirow{3}{*}{ Blank } & $1.0 \mathrm{~mol} / \mathrm{L}$ & 1.002 & - & - \\
\hline \multirow{3}{*}{$\mathrm{AAO}$} & $0.5 \mathrm{~g} / \mathrm{L}$ & 0.196 & 84 & 0.84 \\
\cline { 2 - 5 } & $0.3 \mathrm{~g} / \mathrm{L}$ & 0.294 & 76 & 0.76 \\
\cline { 2 - 5 } & $0.1 \mathrm{~g} / \mathrm{L}$ & 0.562 & 53 & 0.53 \\
\cline { 2 - 5 } & $0.05 \mathrm{~g} / \mathrm{L}$ & 0.632 & 47 & 0.47 \\
\hline
\end{tabular}

In the case of the weight loss method, the inhibition efficiency ( $E_{w} \%$ ) and surface coverage $(\theta)$ were determined by using the following equation:

$$
\mathrm{E}_{\mathrm{W}}(\%)=1-\frac{\mathrm{W}^{\prime} \text { corr }}{\mathrm{W}_{\text {corr }}} \times 100
$$


where $\mathrm{W}_{\text {corr }}$ and $\mathrm{W}^{\prime}$ corr are $\mathrm{C} 38$ steel corrosion rate in $1 \mathrm{M} \mathrm{HCl}$, with and without inhibitor, respectively.

The analysis of the results from Table 4 clearly shows that the corrosion rate $\left(\mathrm{W}_{\text {corr }}\right)$ decreases, while the inhibition efficiency $\left(\mathrm{E}_{\mathrm{w}} \%\right)$ increases with higher inhibitor concentrations, reaching a maximum value of $83.68 \%$, at a concentration of $0.5 \mathrm{~g} / \mathrm{L}$. This behavior can be attributed to the increase in the covered surface $(\theta)$, and to the eco-friendly compounds adsorption onto the metal surface, as the inhibitor concentration increases.

We can conclude that AAO is a good eco-friendly corrosion inhibitor for steel, in a $1.0 \mathrm{M} \mathrm{HCl}$ solution.

\section{Adsorption isotherms}

Basic information on the interaction between the inhibitor and the steel surface can be provided by the adsorption isotherm. The adsorption isotherms are very important for understanding the mechanism of metals' electrochemical reactions [20]. Knowledge on the adsorption type of these inhibitors, and the determination of their thermodynamic parameters, often help to elucidate their mode of action. In order to obtain the isotherm, the linear relation between the degree of surface coverage $(\theta)$ values (Table 4$)$ and inhibitor concentration $\left(\mathrm{C}_{\mathrm{inh}}\right)$ must be found. The most frequently used isotherms are Langmuir, Frumkin, Temkin and Freundlich ones [21]. By far, the best fit was obtained with the Langmuir isotherm. This model has also been used for other inhibitor systems [22-23]. According to this isotherm, $\mathrm{C}_{\mathrm{inh}} / \theta$ is related to $\mathrm{C}_{\mathrm{inh}}$ by:

$$
\frac{\mathrm{C}_{\text {inh }}}{\theta}=\frac{1}{\mathrm{~K}_{\text {ads }}}+\mathrm{C}_{\text {inh }}
$$

The uncharged molecules adsorption onto a heterogeneous surface is appropriately described by the Temkin isotherm.

$$
\theta=\frac{1}{f} \ln \left(K_{a d s} C_{i n h}\right)
$$

where $\theta$ is a linear function of $C_{\text {inh }}$ [24]. This isotherm contains a factor ( $f$ ) that clearly takes in account adsorbent-adsorbates interactions, and the fact that the adsorption heat of all molecules in the layer decreases with the coverage, due to the adsorbate-adsorbent interaction.

Freundlich adsorption isotherm was found to be suitable for the experimental findings; the isotherm is described by the following equation:

$$
\log (\theta)=\ln \left(K_{a d s}\right)+n \ln \left(C_{i n h}\right)
$$

where $\mathrm{C}$ is the inhibitor concentration, $\mathrm{K}_{\mathrm{ads}}$ is the adsorption equilibrium constant, $\theta$ is the surface coverage and $\mathrm{n}$ is the constant. 
The experimental data were graphically tested to fit Langmuir, Temkin and Freundlich adsorption isotherms. For all isotherms, the linear regression parameters are listed in Table 5. A plot of $\log (\mathrm{C} / \theta)$ against $\mathrm{C}$ (Fig. 6(a)) gives a straight line (R2>0.9), indicating that the adsorption followed the Langmuir adsorption isotherm. Apricot almond oil adsorption onto the mild steel surface obeyed Langmuir adsorption isotherm [25-27].

According to this isotherm, the plot of surface coverage $(\theta)$ obtained from the weight loss method versus $\log \mathrm{C}$ at different inhibitor concentrations showed a straight line, which is graphically represented in Fig. 6(b). It indicates that the inhibitor adsorption from an aqueous medium onto the carbon steel surface followed the Temkin adsorption isotherm. From the Temkin data, it was observed that the corrosion inhibition by the inhibitor's compounds results from their adsorption onto the metal surface [28].
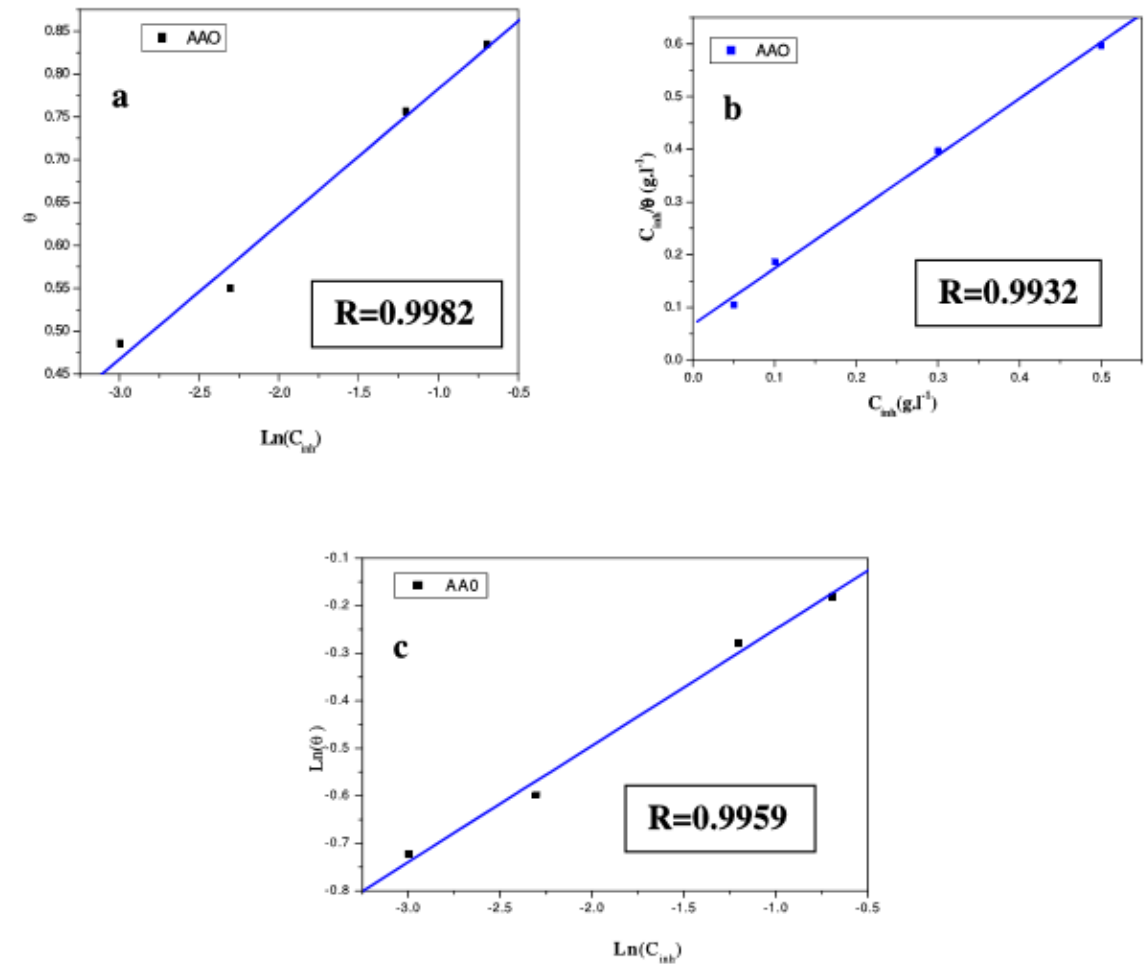

Figure 6. Plots of (a) Langmuir, (b) Temkin and (c) Freundlich adsorption isotherm of AAO onto the steel surface, at $298 \mathrm{~K}$.

Table 5. Thermodynamic parameters for the adsorption of apricot almond oil extract in $1 \mathrm{M} \mathrm{HCl}$, on the carbon steel, at $298 \mathrm{~K}$.

\begin{tabular}{|c|c|c|c|}
\hline Isotherm & $\mathbf{K}_{\text {ads }}\left(\mathbf{M}^{\mathbf{1}}\right)$ & $\mathbf{R}^{\mathbf{2}}$ & $\mathbf{\Delta G}_{\text {ads }}^{\mathbf{o}}(\mathbf{k J} / \mathbf{m o l})$ \\
\hline Langmuir & 14.83 & 0.9982 & -16.62 \\
\hline Temkin & 2.56 & 0.9932 & -24.70 \\
\hline Freundlich & 0.9915 & 0.9959 & -9.92 \\
\hline
\end{tabular}

A plot of $\log \theta$ against $\log \mathrm{C}$ is shown in Fig. 6(c). The linearity shows that the inhibitors adsorption onto the mild steel surface followed Freundlich isotherm [29]. The adsorption studies clearly indicated that the experimental data fitted the 
Langmuir, Temkin and Freundlich adsorption isotherms, the correlation coefficient being greater than 0.90.The adsorbed inhibitors tended to desorb from the mild steel surface [30-31].

The strong correlations $\left(\mathrm{R}^{2}=0.9982 ; \mathrm{R}^{2}=0.9932 ; \mathrm{R}^{2}=0.9959\right.$, respectively, for Langmuir, Temkin and Freundlich isotherms) confirm the validity of this approach. The $\mathrm{K}_{\text {ads }}$ values obtained from the Langmuir, Temkin and Freundlich isotherms are listed in Table 5, together with the Gibbs free energy of adsorption values calculated from the following equation:

$$
\Delta G_{a d s}^{\circ}=-R T \ln \left(55.5 K_{a d s}\right)
$$

where $\mathrm{R}$ is the universal gas constant, $\mathrm{T}$ is the thermodynamic temperature, and the value of 55.5 is the water concentration in the solution [32].

The high value of the adsorption equilibrium constant reflects the high adsorption ability of this inhibitor onto the carbon steel surface. From Eq. (5), $\Delta \mathrm{G}_{\text {ads }}^{\circ}$ was calculated as $-16.62 \mathrm{~kJ} \mathrm{~mol}^{-1}$ (Langmuir), $-24.70 \mathrm{~kJ} \mathrm{~mol}^{-1}$ (Temkin) and $-9.92 \mathrm{~kJ}$ $\mathrm{mol}^{-1}$ (Freundlich), for AAO. The negative value of the standard free energy of adsorption indicates spontaneous adsorption of the molecules onto the carbon steel surface, and also the strong interaction between the inhibitor molecule and the metal surface [33-34]. Generally, the standard free energy values of $-20 \mathrm{~kJ} \mathrm{~mol}^{-1}$, or less negative, are associated to an electrostatic interaction between charged molecules and the charged metal surface (physical adsorption); those of $-40 \mathrm{~kJ} \mathrm{~mol}^{-1}$, or more negative, involve charge sharing or transfer from the inhibitor molecules to the metal surface, to form a coordinate covalent bond (chemical adsorption) [35-36].

$\Delta \mathrm{G}_{\text {ads }}^{\circ}$ values for AAO are in the range from $-9.92 \mathrm{~kJ} / \mathrm{mol}$ to $24.70 \mathrm{~kJ} / \mathrm{mol}$, suggesting that the adsorption involves physisorption interactions.
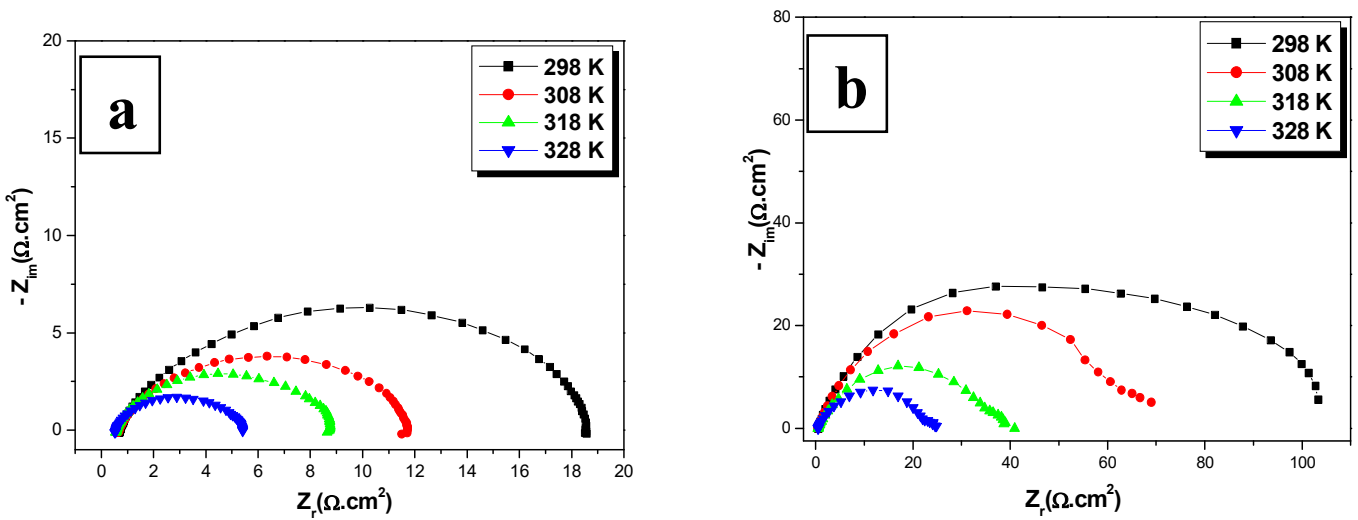

Figure 7. (a) Nyquist plots for steel corrosion in $1 \mathrm{M} \mathrm{HCl}$, at different temperatures, and (b) $0.5 \mathrm{~g} / \mathrm{L}$ of apricot almond oil.

\section{Effect of temperature}

Generally, steel corrosion rate in an acidic solution increases with the rise in temperature. This is due to the decrease in hydrogen evolution over potential [37]. In order to understand more about AAO performance with the nature of 
adsorption and activation processes, the effect of temperature was studied. For this purpose, electrochemical impedance spectroscopy measurements were employed with temperatures of 298, 308, 318 and $328 \mathrm{~K}$, in the absence and presence of $0.5 \mathrm{~g} / \mathrm{L}$ of inhibitor (Figs. $7(\mathrm{a}, \mathrm{b})$ ). It's clear from this figure that the charge transfer resistance of inhibited and uninhibited media diminishes with increased temperature. Corresponding data are given in Table 6.

The various obtained corrosion parameters are listed in Table 6. The obtained data suggest that AAO got adsorbed onto the steel surface at all studied temperatures, and that the rise in temperature led to a decrease in $R_{c t}$ values.

Table 6. Effect of temperature on the carbon steel corrosion in free acid, and at $0.5 \mathrm{~g} / \mathrm{L}$ of apricot almond oil.

\begin{tabular}{|c|c|c|c|c|}
\hline Inhibitor & Temp (K) & $\mathbf{R}_{\mathrm{ct}}\left(\mathbf{\Omega . c m}^{2}\right)$ & $C_{\mathrm{dl}}\left(\mu \mathrm{F} / \mathrm{cm}^{2}\right)$ & $\mathrm{E}_{\mathrm{RT}}(\%)$ \\
\hline \multirow{4}{*}{ Blank } & 298 & 18 & 221 & - \\
\hline & 308 & 11 & 229 & - \\
\hline & 318 & 8 & 199 & - \\
\hline & 328 & 5 & 201 & - \\
\hline \multirow{4}{*}{ AAO } & 298 & 109 & 97 & 84 \\
\hline & 308 & 64 & 165 & 82 \\
\hline & 318 & 37 & 172 & 78 \\
\hline & 328 & 24 & 265 & 79 \\
\hline
\end{tabular}

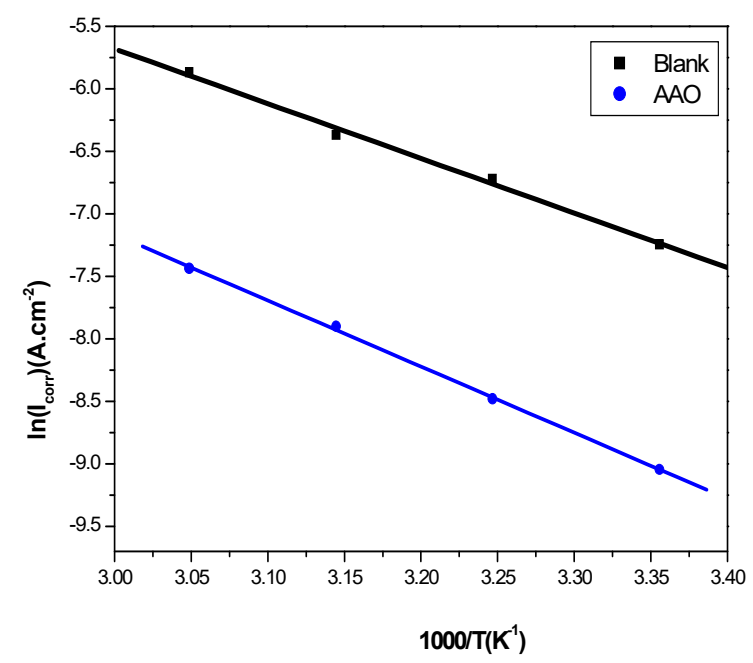

Figure 8. Arrhenius plots of steel in $1 \mathrm{M} \mathrm{HCl}$.

As the corrosion rate was inversely proportional to $\mathrm{R}_{\mathrm{ct}}$ values of $\mathrm{Ln}\left(\mathrm{I}_{\mathrm{corr}}\right)$ and $\mathrm{Ln}$ ( $\left.\mathrm{I}_{\text {corr }} / \mathrm{T}\right)$, they were plotted as a temperature function (Arrhenius plots) in Figs. 8 and 9, for C38 steel corrosion in a hydrochloric acid solution. Ea, $\Delta H_{a}$ and $\Delta S_{a}$ values were estimated from the straight lines slopes, and are given in Table 7.

Inspection of these data reveals that the apparent activation energy $\left(E_{a}\right)$ in a $1 \mathrm{M}$ $\mathrm{HCl}$ solution, in AAO absence, was $36.38 \mathrm{~kJ} / \mathrm{mol}$. AAO addition to the acidic solution increased the activation energy. Note that the increase in the activation energy in AAO presence may be attributed to the AAO inhibitor physisorption onto the C38 steel surface [38-39]. 


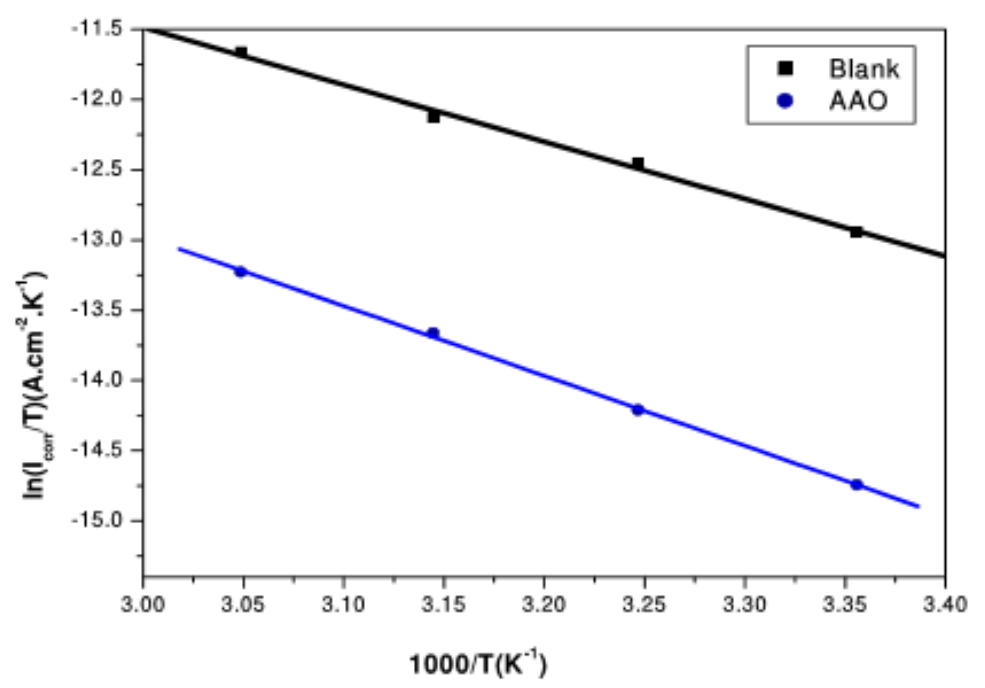

Figure 9. Relation between $\operatorname{Ln}\left(\mathrm{I}_{\text {corr }} / \mathrm{T}\right)$ and $1000 / \mathrm{T}$ at different temperatures $(0.5 \mathrm{~g} / \mathrm{L})$.

Table 7. Values of $E_{a}, \Delta H_{a}$ and $\Delta S_{a}$ activation parameters for $\mathrm{C} 38$ steel in $1 \mathrm{M} \mathrm{HCl}$, in the absence and presence of $0.5 \mathrm{~g} / \mathrm{L}$ of AAO.

\begin{tabular}{|c|c|c|c|c|} 
Inhibitor & $\begin{array}{c}\Delta \mathbf{H}_{\mathbf{a}} \\
(\mathbf{k J} / \mathbf{m o l})\end{array}$ & $\begin{array}{c}\Delta \mathbf{S}_{\mathbf{a}} \\
(\mathbf{J} / \mathbf{m o l})\end{array}$ & $\begin{array}{c}\mathbf{E}_{\mathbf{a}} \\
(\mathbf{k J} / \mathbf{m o l})\end{array}$ & $\mathbf{E}_{\mathbf{a}}-\mathbf{\Delta} \mathbf{H}_{\mathbf{a}}$ \\
\hline $1 \mathrm{M} \mathrm{HCl}$ & 33.79 & -191.53 & 36.38 & 2.60 \\
$\mathrm{AAO}$ & 41.35 & -181.19 & 43.94 & 2.60 \\
\hline
\end{tabular}

On the other hand, the inspection of the same table revealed that the thermodynamic parameters $\left(\Delta \mathrm{S}_{\mathrm{a}}\right.$ and $\left.\Delta \mathrm{H}_{\mathrm{a}}\right)$ for the dissolution reaction of $\mathrm{C} 38$ steel in $1 \mathrm{M} \mathrm{HCl}$, in the inhibitor presence, are lower than those obtained in the inhibitor absence. $\Delta \mathrm{H}_{\mathrm{a}}$ positive sign reflects the endothermic nature of the $\mathrm{C} 38$ steel dissolution process, suggesting that it was slowed [40] down in the inhibitor presence. $\Delta \mathrm{S}_{\mathrm{a}}$ value is greater in the solution with AAO inhibitor, and lower in the uninhibited solution. Some researches explained this behavior by a replacement process of the water molecules during the inhibitor molecules adsorption onto the electrode surface [41]. The thermodynamic reaction between $\mathrm{E}_{\mathrm{a}}$ and $\Delta \mathrm{H}_{\mathrm{a}}$ exposed in Table 7 is verified.

\section{Conclusion}

Apricot almond oil is considered as a green inhibitor for carbon steel in $1.0 \mathrm{M}$ $\mathrm{HCl}$. The inhibition efficiency of this compound obtained by various techniques exceeded $84 \%$, for a concentration of $0.5 \mathrm{~g} / \mathrm{L}$. The majority of the compounds of $\mathrm{AAO}$ are oleic and linoleic acids. The polarization curves classified this compound as a mixed-style inhibitor with anodic predominance. EIS measurements show a single depressed semicircle from high to low frequencies regions, for uninhibited and inhibited solutions, illustrating that the corrosion process was controlled by charge transfer resistance. The increase in the charge transfer resistance $\left(\mathrm{R}_{\mathrm{ct}}\right)$ and decrease in the double layer capacitance $\left(\mathrm{C}_{\mathrm{dl}}\right)$, in the inhibitor presence, can be explained by the inhibitor molecules adsorption onto 
the carbon steel surface. AAO adsorption onto mild steel, in an aqueous medium, obeyed Langmuir, Temkin and Freundlich adsorption isotherms.

\section{References}

1. Hmamou DB, Salghi R, Zarrouk A, et al. Inter J Industrial Chem. 2012;3:25.

2. Afia L, Salghi R, Bazzi E, et al. Int J Electrochem Sci. 2011;6:5918.

3. Lahhit N, Bouyanzer A, Desjobert JM, et al. Port Electrochim Acta. 2011;29:127

4. Bammou L, Chebli B, Salghi R, et al. Green Chem Lett Rev. 2010;3:173.

5. Batah A, Belkhaouda M, Bammou L, et al. Moroccan J Chem. 2017;5:580.

6. Bammou L, Belkhaouda M, Salghi R, et al. J Assoc Arab Univ Basic Appl Sci. 2014;16:83.

7. Belkhaouda M, Bammou L, Salghi R, et al. Int J Electrochem Sci. 2013;8:10987.

8. Afia L, Lgaz H, Zougagh M, et al. Appl J Envir Eng Sci. 2016;2:42.

9. Bammou L, Belkhaouda M, Salghi R, et al. Int J Electrochem Sci. 2014;9:1506.

10. Ouachikh O, Bouyanzer A, Bouklah M, et al. Surf Rev Lett. 2009;16:49.

11. Benali O, Larabi L, Traisnel M, et al. Appl Surf Sci. 2007;253:6130.

12. Lgaz H, Salghi R, Jodeh S. Int J Corros Scale Inhib. 2016;5:347.

13. Larabi L, Harek Y, Traisnel M, et al. J Appl Electrochem. 2004;34:833.

14. Rosliza R, WanNik WB, Senin HB. Mater Chem Phys. 2008;107:281.

15. Shih H, Mansfeld H. Corros Sci. 1989;29:1235.

16. Martinez S, Metikos-Hukovic M. J Appl Electrochem. 2003;33:1137.

17. Quraishi MA, Rawat J. Mater Chem Phys. 2001;70:95.

18. Bentiss F, Lagrene'e M, Traisenl M, et al. Corros Sci. 1999;41:789.

19. Al-Sabagh AM, Abd-El-Bary HM, El-Ghazawy RA, et al. Egypt J Petrol. 2011;20:33.

20. Hackerman N, McCafferty E. Proc 5th International Congress on Metallic Corrosion. Houston, TX; 1974. p. 542.

21. Bilgic S, Caliskan N. Appl Surf Sci. 1999;152:107.

22. Sahin M, Bilgic S, Yilmaz H. Appl Surf Sci. 2002;195:1.

23. Kissi M, Bouklah M, Hammouti B, et al. Appl Surf Sci. 2006;252:4190.

24. Nnanna LA, Owate IO, Nwadiuko OC, et al. Int J Mater Chem. 2013;3:10.

25. Subhashini S. J Cam Prac Res. 2004;11:27.

26. Sivaraju M, Kannan K. Int J Chem Tech Res. 2010;2:1243.

27. Pradeep Kumar CP, Mohana KN. Int Res J Pure App Chem. 2013;3:330.

28. Rosaline Vimala J, Leema Rose A, Raja S. Pelagia Res Lib. 2012;3:602.

29. Zhang D, Cai Q, He X, et al. Corros Sci. 2009;51:2349.

30. Qu Q, Hao Z, Li L, et al. Corros Sci. 2009;51:569.

31. Hegazy MA, Ahmed HM, El-Tabei AS. Corros Sci. 2011;53:671.

32. Ouici HB, Belkhouda M, Benali O, et al. Res Chem Intermed. 2015;41:4617.

33. Olivares O, Likhanova NV, Gomez B, et al. Appl Surf Sci. 2006;252:2894.

34. Avci G. Mater Chem Phys. 2008;112:234.

35. Bayol E, Gurten AA, Dursun M, et al. Acta Phys Chim Sin. 2008;24:2236. 
36. Abiola OK, Oforka NC. Mater Chem Phys. 2004;83:315.

37. Popova A, Sokolova E, Raicheva S, et al. Corros Sci. 2003;45:33.

38. Bousskri A, Anejjar A, Salghi R, et al. J Mater Environ Sci. 2016;7:4269.

39. Sankarapapavinasam S, Pushpanaden F, Ahmed MF. Corros Sci. 1991;32:193.

40. Messali M, Bousskri A, Anejjar A, et al. Int J Electrochem. Sci. 2015;10:4532.

41. Lgaz H, Belkhaouda M, Larouj M, et al. J Chem. 2016;4:101. 